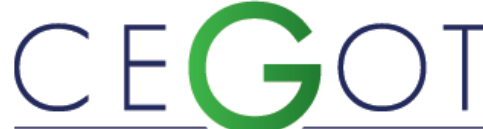

Centro de Estudos de Geografia e Ordenamento do Território
BARBOSA, LEONARDO

Universidade Estadual de Maringá, Departamento de

Arquitetura e Urbanismo

87010-900, Maringá, Paraná, Brasil - Av. Colombo, 5.790 Jd. Universitário

(Bloco 32)

Leonardo.cb@gmail.com

\title{
As redes técnicas sanitárias como reflexo de poder na sociedade capitalista: apontamentos com base na ação da CODEMAR em Maringá, Paraná, Brasil, entre 1962-1980 \\ Sanitary technical networks as representations of power in capitalist society: Notesbased on the activities of CODEMAR in Maringá, Brazil, between 1962 and 1980
}

Referência: Barbosa, Leonardo (2018). As redes técnicas sanitárias como reflexo de poder na sociedade capitalista: apontamentos com base na ação da CODEMAR em Maringá, Paraná, Brasil, entre 1962-1980. Revista de Geografia e Ordenamento do Território (GOT), n. ${ }^{\circ} 13$ (junho). Centro de Estudos de Geografia e Ordenamento do Território, p. 33-58, dx.doi.org/10.17127/got/2018.13.002

\section{RESUMO}

Compreendendo a cidade pelo viés da interação da tecnologia com a sociedade, aborda-se a correlação entre o processo de urbanização e o estabelecimento das redes técnicas sanitárias. A cidade de Maringá foi implantada ex novo, em 1947, por uma empresa de capital privado que se mostrou negligente no provimento de infraestruturas básicas ao seu funcionamento. Assim, analisa-se a atuação da companhia sanitária municipal (CODEMAR Companhia de Desenvolvimento de Maringá), destinada a executar e gerir estes serviços, entre os anos de 1962-1980, com o objetivo de analisar o impacto de suas ações na sociedade, na estruturação do território e nos padrões de crescimento e organização urbana. Os resultados apontam para a falta de neutralidade do poder municipal, corroborando para a criação de uma dicotomia entre a porção planejada e as áreas de expansões da cidade.

Palavras-chave: urbanização, infraestrutura urbana, CODEMAR, abastecimento de água, esgotamento sanitário.

\section{ABSTRACT}

Current research analyzes the city through the interaction between technology and society and deals with the co-relationship between the urbanization process and the establishment of sanitary technical networks. The city of Maringá was established ex novo by a private company in 1947 which proved to be negligent in providing basic infrastructure. CODEMAR, the municipal sanitary company established to administer and execute basic services in the municipality between 1962 and 1980, is analyzed for the impact of its activities on society and for the structuring of the administered territory within patterns of urban growth and 
organization. Results reveal lack of neutrality of municipal government which corroborated with the rise of a dichotomy between the planned section and the city's expanding areas.

Keywords: urbanization, urban infrastructure, CODEMAR, water supply, sanitary sewerage network.

\section{Introdução}

O estudo da cidade moderna tem como ponto de partida a Revolução Industrial (século XVIII). Como observou Lefevbre (2001), o processo de industrialização - e a consequente organização capitalista do espaço - tem sido o agente indutor das transformações da sociedade urbana, refletindo nas problemáticas de crescimento, planejamento e luta de classes nas cidades.

Ainda que as cidades pré-existam à industrialização, foi após o advento desta lógica produtiva que a sociedade iniciou o processo de aglomeração no espaço urbano, tendo como característica a tendência crescente de organização por meio de redes - sanitárias, de eletrificação, de transportes, comunicação, etc. - com bases assentadas na propriedade privada do solo urbano. Joel Tarr (1984) classifica este fenômeno como a transição da walking city, cidade densa, compacta e com baixo grau de infraestrutura, para a networked city, a metrópole industrial, com valores posicionais de uso do solo definidos e altamente conectados por redes.

A abordagem da história urbana sob a ótica da interação entre a tecnologia e fatores sociais, culturais, políticos e econômicos tem sido explorada por autores como Dupuy (1998), Castells (2005) e Secchi (2007). Destes estudos partem o entendimento de que o rígido determinismo tecnológico ou o simples modelo de demanda distorcem o padrão de evolução das infraestruturas, uma vez que o estabelecimento destas na cidade está sujeito a uma série de fatores, como investimentos, políticas públicas e conjuntura econômica, que tornam este processo não linear.

Para Milton Santos (2008, p.24) "O desenvolvimento da história vai de par com o desenvolvimento das técnicas" uma vez que "A cada evolução da técnica, uma nova etapa da história se torna possível". O autor expõe ainda que o surgimento de uma nova família 
de técnicas não elimina as anteriores, pois estas passarão a coexistir sendo que as técnicas mais avançadas serão consumidas pelos atores mais hegemônicos, ao passo que os não hegemônicos utilizarão conjuntos menos atuais, revelando assim uma relação de poder na apropriação do desenvolvimento técnico.

Este viés da materialização de relações de dominação e poder no território, observado nos estudos das redes técnicas, é explorado em diversos trabalhos (Raffestin, 1993; Dupuy, 1998; Castells, 2005; Santos, 2006). A ideia de poder, expressa por estes autores, se dá na capacidade de uma organização controlar recursos necessários ao funcionamento de uma outra organização. Entendendo a rede como um conjunto de nós interconectados, Castells (2005, p.567) afirma que "os conectores são os detentores do poder", pois estes determinam processos de inclusão/exclusão, que repercutem na organização social.

De acordo com Milton Santos (2006), tal fato se deve ao modo de produção capitalista, que dá a alguns atores um papel privilegiado na produção do espaço. Assim, as redes são a materialização no território desta relação, pois ao mesmo tempo em que solidariza e conecta uma parcela ao serviço, exclui e marginaliza os que não the tem acesso. Dupuy (1998) corrobora com este pensamento, afirmando que para os atores econômicos - como as empresas -, a rede é um meio de territorializar para gerar valor - lê-se valor econômico.

Neste sentido, a relação dialética entre valor de uso e valor de troca, se mostra uma variável chave para o estudo urbano. Lefebvre (2001) afirma que a cidade e a realidade urbana dependem do valor de uso. Contudo, a orientação irreversível na direção do dinheiro e da mercadoria do sistema produtivo vigente coloca o valor de troca como força principal, subordinando a si os valores de uso. Com efeito, as redes técnicas sanitárias, inegável valor social de uso, apresentarão uma lógica de implantação no território maringaense mais relacionada com o valor do solo do que com a demanda pelo serviço.

Dentre as redes de infraestrutura urbana, as redes técnicas sanitárias - abastecimento de água, coleta de esgoto e drenagem pluvial -, emergiram no espaço urbano moderno de forma pioneira como uma resposta à insalubridade produzida pela industrialização. De maneira geral, a iniciativa privada se mostrou um importante agente na implantação dos serviços, como no caso do abastecimento de água na Inglaterra, EUA e Brasil, iniciado por empresas privadas, ainda que, nos últimos dois casos, o poder público tenha tomado a 
frente da implantação dos serviços nos primeiros anos do século XX (Melosi, 2008; Rezende e Heller, 2002). Já os serviços de esgotamento sanitário, em razão dos altos custos de implantação, tenderam a ter controle do setor público, embora sempre houvesse forte interesse e pressão da iniciativa privada no estabelecimento destas redes (Dupuy, 1998).

Destas observações vale destacar dois aspectos. O primeiro é o inevitável impacto destas redes no valor do solo urbano, pois como explicado por Villaça (2001), o valor de troca de um determinado espaço reside na quantidade de trabalho social despendido na produção daquela localidade, expresso, dentre outras formas, pelo acesso ao serviço sanitário. 0 segundo aspecto diz respeito à lógica empresarial adotada para os serviços sanitários, que no caso brasileiro se acentuou com o Plano Nacional de Saneamento (PLANASA), que entrou em funcionamento em 1971, conferindo monopólio às companhias estaduais, únicas a terem acesso ao Sistema Financeiro de Financiamento (SFS) (Rezende e Heller, 2002).

Assim, a implantação das redes sanitárias no território se mostra vantajosa para diversos atores urbanos, como os promotores imobiliários - visando ampliar o valor de troca -, a população em geral - pela qualidade de vida proporcionada pelo serviço - e pelo Estado. Sobre este último é importante destacar a complexidade de sua atuação, uma vez que que atua como promotor de uma série de serviços e infraestrutura urbanos; regula e disciplina o uso e ocupação do solo; e ainda age como proprietário fundiário e promotor imobiliário, consumindo espaço e localizações específicas (Corrêa, 1999).

O estudo da história urbana, por meio do estabelecimento das redes sanitárias no território, se mostra uma frutífera ferramenta para tecer análises acerca dos padrões de crescimento urbano, história e evolução da técnica, e as relações de poder estabelecidas por diferentes agentes. Como objeto de estudo, elegeu-se a cidade de Maringá, localizada no estado do Paraná, Brasil, cidade implantada ex novo em 1947, fruto de um plano de colonização empreendido por agentes privados.

As infraestruturas e serviços urbanos demoraram a se estabelecer na cidade, pois a companhia colonizadora limitava-se a traçar os arruamentos e dividir os lotes nas cidades que implantava. Estes serviços ficavam, então, a cargo das municipalidades que com poucos recursos nos anos iniciais e frente a um expressivo crescimento populacional, demoram a resolver estas questões, gerando dificuldades no cotidiano da população e entraves ao 
desenvolvimento econômico da urbe. No que tange as questões sanitárias, a solução só começou a ser solucionada no fim de 1962, com a criação da Companhia de Desenvolvimento de Maringá (CODEMAR), empresa sanitária municipal destinada a implantar e gerir estas infraestruturas no município.

Assim, o objetivo deste estudo é entender o impacto das redes técnicas sanitárias implantadas pela CODEMAR na sociedade, estruturação do território e padrões de crescimento e organização urbana, uma vez que, a abrangência destes serviços, intimamente relacionados com a salubridade e qualidade de vida, pode materializar no espaço relações de poder, dominação e exclusão social.

O recorte temporal elegido consiste no período de atuação da CODEMAR em Maringá, iniciando em dezembro de 1962, quando é criada, até junho de 1980 quando a concessão dos serviços sanitários é repassada à Companhia de Saneamento do Paraná (SANEPAR). O método de análise consistiu no confrontamento entre diferentes fontes documentais, como jornais de veiculação diária da época, mapas e projetos das redes sanitárias, diagnósticos de planos diretores, legislação urbanística e a iconografia disponível, buscando a correlação do processo de urbanização com o estabelecimento das redes sanitárias no território.

\section{A atuação da CODEMAR na cidade de Maringá}

A análise aqui proposta é dividida três recortes temporais. O primeiro, de 1947 a 1962, visa explicitar o contexto de formação da cidade de Maringá e seus anos iniciais de funcionamento, encerrando com a criação da CODEMAR. O segundo, de 1962 a 1969, discorre sobre a fase de estruturação da empresa na cidade, finalizando em 1969 quando o sistema de abastecimento de água começa a operar. A última fase (1969-1980) investiga o processo de implantação das infraestruturas sanitárias na cidade, explorando sua relação com a forma e crescimento urbano, o impacto destas redes na sociedade e a atuação do poder municipal enquanto agente no provimento destes serviços. 


\subsection{A construção de Maringá e a conjuntura para a instalação das redes sanitárias}

A cidade de Maringá está situada na região Norte do Paraná, porção do Estado colonizada a partir de 1925, por um empreendimento privado, coordenado pela Companhia de Terras Norte do Paraná (CTNP) - posteriormente denominada Companhia Melhoramentos Norte do Paraná, CMNP -, que se destaca em nível nacional pela dimensão e característica do plano realizado. Estas interviram em uma área de 546.017 alqueires, executando o parcelamento rural e criando uma rede de mais de 60 novos núcleos urbanos (Rego, 2009).

Antes deste plano de colonização, esta porção do estado era constituída por terras devolutas, ocupadas por posseiros e indígenas. Seu processo de ocupação foi motivado, sobretudo, pela fertilidade do solo, atrativo para a expansão da produção cafeeira do sul paulista, e pela intenção do governo do estado de ocupação destas áreas, vendendo a preços módicos para companhias colonizadoras privadas. Não cabe aqui o aprofundamento do complexo e conflituoso processo de ocupação regional, explorado por estudos de enfoques variados como os de Monbeig (1984), Mota (2005), Gonçalves (2007) e Rego (2009) mas é importante destacar que o aparente sucesso da rede urbana estabelecida pelas colonizadoras foi conseguido à custa de significativas perdas ambientais - devastação da Mata Atlântica - e sociais - expropriação de indígenas e posseiros.

O plano traçado pela CTNP/CMNP utilizou como linha mestra a demarcação de uma ferrovia, implantada no divisor de águas de duas bacias, a do Rio Ivaí ao sul e do Rio Pirapó ao norte. Junto à ferrovia, conformou-se o transporte rodoviário, também seguindo o espigão e ramificando-se em estradas de menor expressão, que seguiam os espigões secundários. As cidades foram hierarquizadas por porte, a saber: quatro cidades polo prestadoras de serviços, distando $100 \mathrm{~km}$ entre si, sendo elas Londrina, Maringá, Cianorte e Umuarama; e núcleos menores situados entre estas, espaçados a cada 15 km (Rego, 2009).

A concepção do plano urbanístico de Maringá ficou a cargo do engenheiro paulistano Jorge de Macedo Vieira, formado pela escola politécnica de São Paulo, profissional extremamente atuante entre as décadas de 1920 e 1960, com projetos de bairros jardins, estâncias balneárias e cidades novas. Suas soluções projetuais apresentam um hibridismo de ideias que perpassa o higienismo, o city beautiful, o zoning, e o ideário de cidade jardim, referências estas que ressoam no plano de Maringá, pensado para acomodar 200.000 
habitantes (Andrade et al. 1999). A modernidade expressa no traçado da cidade foi intensamente propagandeada pela companhia colonizadora.

O processo de ocupação de Maringá, prosperou com grande rapidez. O núcleo inicial Maringá Velho foi implantado em 1942 como subsídio para a abertura da "cidade oficial", composta pelo plano moderno de Macedo Vieira, inaugurado em 1947. Em 1951, a cidade já se elevava à categoria de município, deixando de ser distrito de Mandaguari. Em termos populacionais, o crescimento urbano foi notável. Em 1950 tinha-se 7.270 habitantes na área urbana e 31.318 hab. na área rural; em 1960, o número sobe para 47.592 hab. urbanos e 56.539 hab. rurais; em 1970, já ocupavam a área urbana 100.100 hab., com a área rural apresentando um decréscimo populacional, ocupada por 21.274 hab.; e, por fim, em 1980, alcançou-se 160.688 hab. na cidade, com apenas 7.550 pessoas residindo no campo. Diversos novos loteamentos surgiram já na primeira década de existência, ofertando lotes de menor custo do que na área planejada, desconfigurando o traçado urbano inicial (IBGE, Censos de 1950, 1960, 1970, e 1980).

Este rápido crescimento - em termos populacionais e de área - trouxe grande dificuldade no provimento de infraestruturas e serviços necessários ao desenvolvimento da cidade. Como demonstrado por Luz (1997), a CMNP se limitava a traçar os arruamentos, dividir os lotes e colocar os meios fios nos núcleos urbanos que implantava. As demais infraestruturas ficavam a cargo das incipientes municipalidades que, com limitações orçamentárias, não conseguiam prover os serviços a contento. Cordovil (2010) coloca que, um dos objetivos da Companhia após a emancipação dos núcleos urbanos que fundava era conseguir apoio político, visando a não taxação de suas terras - principalmente a incidência do Imposto Predial e Territorial Urbano (IPTU). Em Maringá, os candidatos à prefeitura por ela apoiados nunca se elegeram, causando maior dificuldade na implantação de infraestruturas pois, nas cidades em que conseguiam apoio político, por vezes a Companhia implantava melhorias para justificar a não taxação de suas propriedades.

Com orçamento inicial limitado e sem o apoio da CMNP - principal agente financeiro à época -, a realidade urbana dos novos moradores constrastava com a modernidade do plano inicial. Infraestruturas básicas como asfaltamento, drenagem pluvial, eletrificação, abastecimento de água e coleta de esgoto demoraram a se estabelecer na cidade, causando grandes dificuldades e transtornos à população, em especial nas décadas de 1950 e 1960. 
No que tange as questões sanitárias, foco deste estudo, observou-se que nos anos iniciais do município as soluções eram tomadas na escala do lote, por iniciativa dos próprios proprietários, com a adoção de poços rasos e fossas negras, técnicas estas bastante rudimentares. Captando a água do lençol freático mais raso - acima do nível da rocha - e executando fossas sem qualquer tipo de proteção, a água consumida, no início de 1960, apresentava problemas de contaminação (Barbosa, 2016a).

As áreas mais consolidadas eram as que apresentavam as condições mais graves em razão da concentração de fossas. Além da poluição da água consumida, esta já se mostrava escassa por volta de 1960, com a secagem constante de poços que frequentemente tinham que ser aprofundados. Neste cenário começa a atuar a iniciativa privada, executando poços semiartesianos que muitas vezes se tornavam redes particulares, distribuindo água para lotes vizinhos mediante cobrança de taxas. Esta prática, contudo, atendia apenas a população de maior poder aquisitivo, em razão dos custos do serviço (Barbosa, 2016a).

A população de menor renda continuava a depender das poucas iniciativas do poder municipal para resolver a questão, como a distribuição de água em caminhões-pipa no ano de 1960. A ação definitiva para os problemas sanitários do município só veio em 14 de dezembro de 1962, com a Lei Municipal n²36/62 que criou CODEMAR, empresa de capital misto, majoritariamente municipal, destinada a projetar, executar e administrar os serviços de abastecimento de água e esgotamento sanitário na cidade. A empresa atuou em Maringá entre 1962 e 1980, quando a concessão de seus serviços foi repassada para uma companhia estadual, a SANEPAR.

\subsection{O processo de estruturação da CODEMAR (1962-1969)}

A construção do espaço urbano - enquanto território que reflete a apropriação de uma sociedade regida pelo modo de produção capitalista - ocorre, principalmente, em função da ação, interesses e influências de uma série de agentes que produzem e consomem este espaço. No caso das infraestruturas sanitárias, conforme demonstrado por Rezende e Heller (2002), o Estado foi, no Brasil, um ator hegemônico, articulando o financiamento, implantação e administração dos sistemas em diferentes níveis - municipal, estadual e federal - a depender da época de análise. 
Embora a iniciativa privada tenha um importante papel na construção do território maringaense, seja pelo papel colonizador da CTNP/CMNP ou, no caso específico da água, com os agentes e empresas ligados à exploração desta por meio de poços semiartesianos e redes particulares, a municipalidade sempre demonstrou saber a importância da estruturação dos serviços sanitários para o desenvolvimento da cidade. Como observou Cordovil (2010), a questão da água foi assunto de pauta das duas primeiras gestões municipais que, por motivos financeiros, não conseguiram empreender uma solução definitiva para o município. Tão logo teve a capacidade político-administrativa e financeira para implantação dos sistemas, a gestão comandada pelo prefeito João Paulino Vieira Filho (1960-1964), iniciará as ações visando à implantação e controle das redes sanitárias.

A criação da CODEMAR, em dezembro de 1962, foi a solução definitiva para sanar os problemas de abastecimento e esgotamento sanitário da cidade. A Companhia era uma sociedade de economia mista, atuante na qualidade de concessionária de serviços públicos, com capital inicial de $\operatorname{Cr} \$ 50.000 .000,00$ (cinquenta milhões de cruzeiros) divididos em 50.000 (cinquenta mil) ações ordinárias, das quais a prefeitura subscrevia $51 \%$ (25.500 ações), ficando as outras à disposição do público interessado. Cada ação de $\operatorname{Cr} \$ 1.000,00$ dava direito a um voto nas decisões das Assembleias Gerais, o que pouco significava, pois sempre prevaleceria a decisão do poder público (O Jornal de Maringá, 6 jan. 1963).

A estrutura administrativa da Companhia era composta por uma diretoria com três membros: diretor-presidente, diretor-financeiro e diretor técnico, que eram eleitos pela Assembleia Geral com mandato de dois anos, podendo ser reeleitos. Havia ainda um conselho administrativo formado por cinco membros, sendo: um usuário, um engenheiro, um vereador, um membro da Associação Comercial, e o Diretor da Companhia. O representante da sociedade (usuário), o engenheiro e o membro da Associação Comercial, eram indicados pelo prefeito, e o vereador, indicado pela Câmara de Vereadores, revelando, assim, um amplo controle público na administração da CODEMAR. Por fim, havia o conselho fiscal, composto de três membros, eleitos pela assembleia geral, com mandato de um ano.

Institucionalizada a empresa de saneamento municipal, iniciou-se o processo de organização interna e de implantação das infraestruturas necessárias para o seu funcionamento. Priorizou-se, inicialmente, o sistema de abastecimento de água, serviço este urgente em razão da contaminação do lençol freático devido a concentração de fossas 
negras na cidade. $\mathrm{O}$ esgotamento sanitário ficou para uma etapa posterior pois, além do custo de implantação mais elevado e menor impacto na qualidade de vida da população, tecnicamente dependia do fluxo hidráulico da água servida, para seu funcionamento.

O projeto do sistema de abastecimento de água foi entregue em outubro de 1963, sendo de autoria do Escritório Técnico Alvaro Cunha - Consultores em Engenharia Sanitária, situado na cidade de São Paulo. O projeto propôs a captação das águas do rio Pirapó, rio intermunicipal com extensão de 168 km, à época distante cerca de 14 km da área urbana de Maringá. O sistema de captação utilizava 6 conjuntos elevatórios, sendo planejada sua implantação em duas etapas: a primeira para a metade da capacidade (3 conjunto elevatórios para abastecer cerca de 100.000 habitantes); e a segunda para capacidade final (6 conjuntos elevatórios para cerca de 200.000 hab.) (E. T. Alvaro Cunha, 1963).

A Estação de Tratamento de Água (ETA) foi locada em uma gleba às margens da avenida Pedro Taques, na Vila Morangueira, bairro recentemente aberto na porção norte da cidade. Para o sistema de distribuição foi proposta a construção de dois reservatórios enterrados e duas torres, locando um conjunto junto à ETA e outro no ponto mais elevado da cidade, em uma rotatória na Zona 5. A rede de distribuição abrangia cerca de $300 \mathrm{~km}$ de vias públicas, sendo dividida em 5 setores. Para efeito de dimensionamento, adotou-se o consumo diário de 200 litros/habitante/dia (E. T. Alvaro Cunha, 1963).

O projeto de abastecimento abrangia a área do plano inicial e as principais expansões ao norte - a Vila Santo Antônio, o Jardim Alvorada e a Vila Morangueira -, as porções mais consolidadas no momento de sua elaboração. Outros loteamentos periféricos, como as Vilas Valência, Santa Isabel, Progresso, Esperança e Emília, não faziam parte dos setores iniciais, provavelmente por sua ocupação ainda rarefeita e desconexa do plano inicial, que não justificava investimento à época.

Ao longo da década de 1960, a CODEMAR concentrou-se em sua estruturação interna e implantação das infraestruturas necessárias para o início do abastecimento, como: barragem; tomada d'água; adutora; estação de tratamento; reservatórios e redes de distribuição. As obras, iniciadas em 1964, perduraram até 1969, quando o abastecimento começa a operar parcialmente na cidade. Já o esgotamento sanitário, efetivou-se ainda mais tardiamente, iniciando seu funcionamento em 1974. 
Antes mesmo de entrar em funcionamento, a Companhia já tomava medidas legais para garantir-se como ator hegemônico quando sua rede começasse a operar. Este é o caso da promulgação da Lei $n^{\circ} 384$ de 1965, que disciplinava o funcionamento de poços artesianos e semiartesianos no perímetro urbano de Maringá. De maneira geral, a lei criava dificuldades para a abertura de redes coletivas particulares na cidade, exigindo: autorização municipal; firma com sociedade registrada; informação do número de usuários atendidos e a taxa cobrada; e aprovação do projeto da rede junto à CODEMAR, no intuito de que se adotassem medidas usuais pela companhia municipal, a fim de aproveitamento futuro das instalações por esta. Ademais, o Art. $4^{\circ}$ informava que a licença concedida à exploração de poços, no município, seria sempre a título precário, revogável ou rescindível a qualquer momento pelo poder público, não cabendo qualquer direito à indenização contra o município pelas obras de abastecimento particulares realizadas.

Em suma, entre 1947 e 1969, a cidade de Maringá, que cresceu exponencialmente nestes anos, não conseguiu prover satisfatoriamente as infraestruturas sanitárias essenciais. A situação era crítica no início da década de 1960, com as águas menos profundas contaminadas pelas fossas negras, tendo acesso à água de melhor qualidade apenas a parcela da população que podia contar com poços semiartesianos. Estes eram efetivados por meio de redes de distribuição particulares, que se concentravam nas áreas mais valorizadas da cidade - principalmente centro, Zona 2 e Zona 4 - em razão do seu elevado custo, evidenciando assim o contraste de renda no espaço urbano. Mesmo com as dificuldades impostas pela Lei $n^{\circ} 384 / 1965$, estas irão perdurar até o início da década de 1970, quando a municipalidade empreende um conflituoso processo de eliminação destas, para garantir a consolidação de sua rede (Barbosa, 2016b).

Corrobora para a precariedade de acesso à água na cidade, o diagnóstico da Comissão de Desenvolvimento Municipal (CODEM) (1997, p.212), para o Plano Diretor de Desenvolvimento de Maringá ${ }^{1}$, em 1967, que classificava a situação da água, como "extremamente grave, constituindo inclusive num entrave ao desenvolvimento". Destacava que a população utilizava-se dos poços semiartesianos, ressaltando que este não era acessível para todos. Para a população de menor renda restava, então, a esperança de ação do poder municipal.

\footnotetext{
${ }^{1}$ Primeiro plano diretor elaborado para o município, instituído pela Lei n621 de 1968.
} 
Importante salientar que, em tese, o projeto de abastecimento encomendado pela CODEMAR contemplava a cidade de maneira global, não fazendo distinções aparentes entre os bairros da cidade, incluindo os loteamentos mais consolidados, fora do limite da área planejada. Contudo, como destacado por Corrêa (1999) a complexidade de atuação do Estado como agente promotor do espaço urbano compromete a sua neutralidade, traduzindo-se em uma ação desigual no território no momento de implantação destes serviços.

\subsection{O processo de implantação das redes de abastecimento de água e esgotamento sanitário e sua repercussão no território (1969-1980)}

Frente ao cenário traçado, fica evidenciado que os sistemas sanitários demoraram a se estabelecer em Maringá. Quando a rede de abastecimento de água começou a operar, em 1969, a cidade se mostrava um importante polo regional, com população urbana na casa dos 100.00 habitantes. Ao longo da década de 1970, a cidade continuou apresentando altas taxas de crescimento demográfico, atingindo 168.194 habitantes em 1980, estando 95,5\% destes na cidade. Esta situação repercutiu no território, em termos de adensamento, crescimento horizontal e vertical, consumindo áreas não urbanizadas e aumentando a demanda por infraestruturas e serviços.

Para analisar a repercussão da instalação da rede da CODEMAR no território maringaense, faz-se necessário um entendimento de sua forma e ocupação urbana no período de sua atuação. Como observou Lamas (2004), o traçado urbano é o primeiro contato que uma cidade estabelece com seu território, transformando a paisagem. Seu forte sentido de permanência no tempo e sua função intrínseca de acomodação e circulação de pessoas, ideias e bens, faz com que sua leitura histórica seja um importante ferramental no entendimento do processo de crescimento urbano. As redes técnicas, por sua vez, emergem subordinadas à morfologia urbana, por surgirem após a conformação dos tecidos e se localizarem acima ou abaixo do nível do solo (Dupuy, 1998). Assim, a correlação que se busca diz respeito aos processos de urbanização, como: o tempo de configuração das porções urbanas; relação entre a área urbana e o meio natural; a demanda por 
infraestrutura, expressa pelo grau de adensamento construtivo e demográfico; e as características sócio espaciais dos distintos bairros.

Concomitante com a abertura da porção planejada, ação que perdurou até o início da década de 1960, novos loteamentos surgiram no seu entorno próximo, estruturados por estradas rurais que os conectavam até a "cidade oficial", mostrando o interesse de outros agentes em lucrar com o parcelamento do solo. Nunes (2016) demonstrou que na maior parte dos casos, os empreendimentos pertenciam a funcionários do auto escalão da CMNP, revelando a ausência de preocupação desta em manter a conformação planejada. As expansões mais significativas localizavam-se na porção norte, com destaque para o Jardim Alvorada e Vila Morangueira, abertos nos primeiros anos de 1960, que juntos acresciam uma área urbanizada de 485,6 ha, acréscimo este significativo, uma vez que a área planejada possuía cerca de 1250 ha.

Esta nova forma urbana emergente era tentacular e fragmentada, o que rapidamente desconfigurou o plano inicial. Em geral, os novos loteamentos apresentavam padrões urbanísticos - dimensão de lotes, largura das vias e disponibilidade de espaços livres inferiores ao observado no plano urbano de Macedo Viera, que se refletia em um menor valor do solo. Importante ressaltar que, somente após a promulgação da Lei Municipal de Loteamentos (Lei n625 de 1968), passou-se a exigir a execução, por parte do loteador, de infraestruturas, como: galerias para drenagem pluvial; rede de energia e iluminação pública; e rede de água. Criava-se assim uma dicotomia - área planejada $X$ novos loteamentos - que, como veremos, será reforçado pela política de implantação das redes sanitárias.

Tal fato pode ser observado já no diagnóstico da CODEM (1967, p.197), que atribui à especulação imobiliária o interesse na criação de novos parcelamentos:

Verificou-se então, o afastamento para a periferia das populações de menor nível de renda, tornando assim propício o aparecimento de "Loteamentos Populares" que, para serem acessíveis àquelas classes, localizaram-se geralmente longe da cidade e com inúmeras deficiências quanto aos requisitos urbanísticos, sacrificados sempre pelo aproveitamento do maior número possível de lotes.

Assim, em termos de valor do solo, a cidade apresentava valores mais elevados na área planejada, em especial na Zona 1 (área central) e suas adjacências e a Zona 2 (bairro de alto padrão), ao passo que os valores mais baixos se concentravam em bairros fora dos limites do plano inicial. Em termos de densidade construtiva, é possível afirmar que as Zonas 1, 2, 3, 
4, 7, 8, Vila Santo Antônio, Vila Esperança, apresentavam-se consolidadas; com ocupação mediana haviam as Zonas 5 e 6, Jardim Alvorada e as vilas Emília, Morangueira, Marumbi, Progresso e Nova; já as demais localidades, apresentavam ocupação ainda rarefeita (Figura 1). Com relação à densidade demográfica destacavam-se a Zona 3 e Zona 7 (variando de 96 a 160 hab./ha), bairros estes classificados como ocupação de baixo padrão, seguidos da Zona 1 e 2 (60 a 85 hab./ha) (CODEM, 1967, prancha U5 e U6).

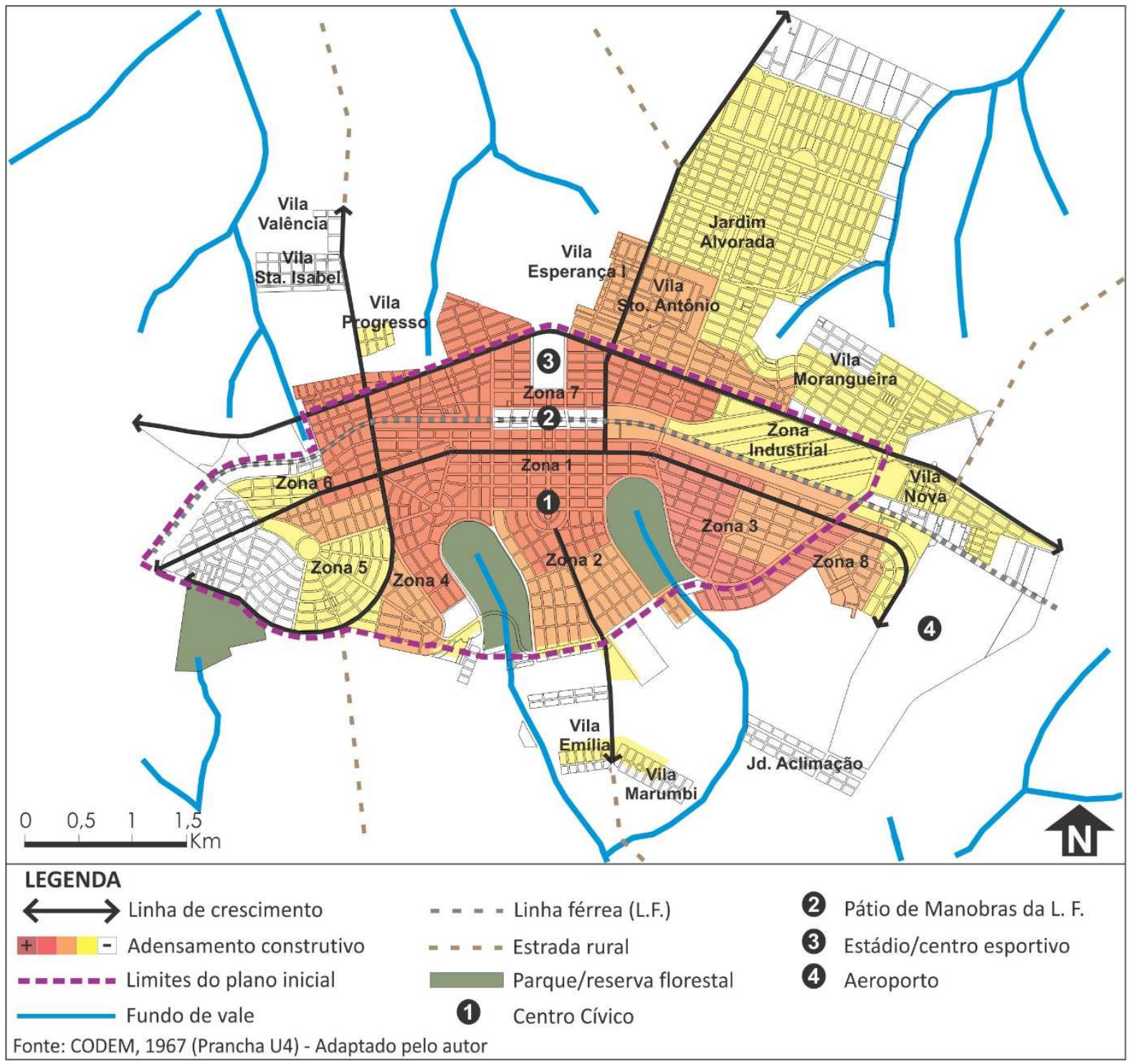

Figura 1 - Forma urbana e adensamento construtivo de Maringá, em 1967

Feitos estes apontamentos, analisemos o processo de implantação dos sistemas sanitários. A rede de abastecimento de água começou a operar no início 1969, atendendo a Zona 1 (67\%) e a Zona 2 (75\%) (O Jornal de Maringá, 23 fev. 1969). A implantação das redes de distribuição nestes bairros revela que, inicialmente, privilegiaram-se as áreas de maior 
interesse econômico: o centro, área densamente ocupada que concentrava os estabelecimentos comerciais e de serviços, que se encontrava em processo de verticalização, e era a área mais afetada pela contaminação causada pelas fossas; e a Zona 2, bairro de alta renda, cuja maior parte da rede já se encontrava assentada - custeada pelos moradores, em conjunto com o asfaltamento das vias, no início da década de 1960.

Ao observar os dados de implantação da rede de distribuição de água nos anos de 1969 e 1971 (Maringá llustrada, 1972), é possível afirmar que a lógica de implantação da rede da CODEMAR era a de atender inicialmente as áreas de maior interesse econômico - centro e bairros de alta renda - e, após, expandir os serviços para as áreas de maior demanda dentro dos limites da área planejada. Desta forma, após o atendimento completo das Zonas 1 e 2, os trabalhos se concentraram nas Zonas 3, 4, 7. A explicação para o atendimento destas porções num segundo momento, aparentemente, são em razão das Zonas 3 e 7 apresentarem as maiores densidades demográficas da cidade, e a Zona 4 ter ocupação de alta renda. Ao final de 1971, a CODEMAR possuía 8.500 ligações de fornecimento de água.

O período entre 1972 e 1974, consistiu na consolidação dos serviços de abastecimento de água dentro da área planejada e início de sua expansão para os loteamentos mais consolidados - Jardim Alvorada e Vila Morangueira - fora desta. Em meados de 1974, foi inaugurado o Reservatório Elevado 2, última importante obra do sistema de distribuição. Com 300.000 litros de capacidade, destinava-se a atender as porções mais elevadas das Zonas 5 e 6, e as expansões ao sul, no eixo da Av. Carlos Corrêa Borges. Na solenidade de inauguração, anunciava-se que ao superar as 18 mil ligações a CODEMAR havia se tornado autossuficiente, em termos financeiros (O Diário do Norte do Paraná, 9 out. 1974).

A busca pela autossustentação tarifária, conseguida pela CODEMAR em 1974, é originária da política inserida na época do Regime Militar (1964-1985), frente ao desequilíbrio existente entre oferta e demanda na área do saneamento. Assim, adotou-se uma visão fortemente empresarial para este setor, por meio de empresas de economia mista e programas como o Plano Nacional de Saneamento (PLANASA), criado em 1971. Ao eleger as companhias estaduais para se ter acesso ao Sistema Financeiro de Financiamento (SFS), o PLANASA se mostrou um meio de centralizar os serviços de água no poder do Estado, forçando a transferência da gestão municipal para companhias estaduais, tornando estas o modelo preponderante no Brasil (Rezende e Heller, 2002). 
O estado do Paraná, por meio da SANEPAR, fazia parte do PLANASA desde 1972. No início de 1975, dos 174 sistemas de saneamento existentes no Paraná, 67 eram operados pela SANEPAR, e outros 60 já possuíam contratos assinados, outorgando a concessão. Além disso, 45 cidades que não possuíam sistema sanitário já haviam assinado contrato de concessão com a empresa estadual (O Diário do Norte do Paraná, 3 abr. 1975).

A cidade de Maringá não aderiu ao PLANASA, sendo assim uma exceção no âmbito estadual e mesmo no federal pois, como visto nos dados de Rezende e Heller (2002), no Brasil, apenas $25 \%$ dos municípios que detinham serviços sanitários não aderiram ao plano federal, ficando excluídos dos financiamentos oferecidos pelo programa, e tendo que suportar a pressão pela adesão dos governos estaduais.

É difícil precisar os reais motivos pelos quais a cidade não aderiu ao programa. Possivelmente fosse mais interessante manter a empresa ligada à gestão municipal, principalmente após ter implantado as partes mais custosas do sistema - captação e tratamento - e ter atingido o número de ligações suficientes para sua autossuficiência. A aparente boa relação política dos gestores municipais também ajudava no avanço da CODEMAR, uma vez que a empresa sempre viabilizou os financiamentos necessários, com órgãos de diferentes esferas. Ademais, a CODEMAR se mostrava um importante "instrumento de campanha", com suas realizações extensamente propagandeadas nos jornais de circulação diária, como sinônimos de progresso da cidade, "creditados na conta" dos diretores da companhia e do governo municipal (Barbosa, 2016a).

A não adesão ao PLANASA não se mostrou um entrave à viabilização dos serviços sanitários. No final de 1974, quando a maior parte da área planejada já possuía rede de abastecimento de água, começa a operar o sistema de coleta de esgotos. O projeto de coleta, afastamento e disposição final do esgotamento sanitário, ficou a cargo da PLANIDRO Engenheiros Consultores S.A. (1963-1976), escritório paulistano formado pela associação de importantes engenheiros sanitários da época, como Alvaro Cunha, José Martiniano de Azevedo Netto, Max Lothar Hess, José Maria Costa Rodrigues e Sizenando Ribeiro.

O sistema de esgotamento sanitário concebido pela PLANIDRO previa cerca de $180 \mathrm{~km}$ de redes, divididas em 3 setores principais, sendo eles: Bacia do Córrego Mandacaru (Estação de Tratamento de Esgoto 1 - ETE 1); Bacia Ribeirão Pinguim (ETE 2), Bacia do Ribeirão 
Morangueiro (ETE Alvorada). A ETE 2, localizada na porção sul do município, próximo à confluência dos Córregos Betty e Moscados, ambos afluentes do Ribeirão Pinguim, foi a primeira instalada, em 1974. A obra era orçada em Cr\$30.350.000,00 (trinta milhões, trezentos e cinquenta mil cruzeiros) (O Diário do Norte do Paraná, 12 nov. 1974).

As obras começaram no início de 1974, sendo a rede inaugurada em 10 de novembro do mesmo ano (Folha do Norte do Paraná, 10 nov. 1974). O início de funcionamento do esgotamento sanitário era apresentado como a solução do grave problema ambiental da cidade, gerado pela presença de mais de 40.000 fossas, que contaminavam o solo e o lençol freático. Em casos mais graves, chegavam a comprometer a estrutura de edifícios, principalmente na Zona 1, que estava em processo de verticalização. Novamente as primeiras áreas atendidas foram a área central (Zona 1) e a Zona 2 (O Diário do Norte do Paraná, 13 nov. 1974), reafirmando a lógica de atendimento prioritário às áreas de maior valor econômico, ainda que sua instalação no centro fosse de fato uma necessidade.

A rede de coleta foi, em parte, paga pelos moradores dos bairros servidos, sendo que a cobrança variava de acordo com a densidade demográfica e o tamanho médio dos lotes da área. De acordo com a CODEMAR, da taxa estipulada, $70 \%$ do valor caberia aos usuários e os 30\% restantes seriam proporcionados pela Prefeitura (O Diário do Norte do Paraná, 8 abr. 1975). A lógica de implantação da rede, assemelha-se a observada no caso da distribuição de água. Em abril de 1975, com as Zonas 1 e 2 completamente atendidas, iniciava-se o funcionamento parcial nas Zonas 3 e 4, e as obras já se encontravam em andamento nas Zonas 5, 7 e 8 (O Diário do Norte do Paraná, 10 abr. 1975).

A prioridade de atendimento da porção planejada da cidade, pode ser observada ainda no fato da ETE 2 ter sido implantada primeiro que a ETE 1. A explicação se dá por razões topográficas, pois a ETE 2 era tecnicamente mais viável para o atendimento da maior parte da área do plano inicial - região ao sul da linha férrea que já havia sido priorizada no atendimento de abastecimento de água, o que agora justificava novamente sua prioridade para o serviço de esgoto -, ao passo que a ETE 1, atenderia principalmente as grandes expansões do setor norte, que concentrava a população de menor renda. Excetuando o fato do abastecimento de água estar mais presente no setor ao sul da linha férrea e de este também apresentar maiores índices de densidade construtiva, neste momento, o setor ao norte já o superava em termos de área urbanizada, tendo aproximadamente 1760 ha de 
área, ao passo que o sul possuía cerca de 1540 ha. A ETE 1 foi inaugurada 1977, quando o município já contabilizava cerca de 8.500 ligações de esgoto.

Em meados da década de 1970, com a área planejada praticamente toda atendida pelo abastecimento de água e o esgotamento sanitário operando parcialmente nesta, a valorização do solo já se refletia na segregação socioespacial. Uma reportagem do jornal Folha do Norte do Paraná (7 abr. 1974), levantava esta preocupação afirmando que, na primeira metade da década de 1970, houve na cidade uma valorização imobiliária média de $300 \%$ a 500\%. O periódico destacava que as Zonas 1, 2 e 5, haviam se tornado áreas "aristocráticas" e, com a saturação destes espaços, as classes médias passaram a ocupar áreas antes ocupadas por classes mais baixas, como a Zona 7.

Apontava-se a especulação imobiliária e a oferta de infraestrutura como as causas principais. A primeira tornou-se uma prática recorrente na cidade, uma vez que o investimento em imóveis havia se tornado um negócio bastante lucrativo. Mesmo com o alto índice de aluguel praticado - em torno de 1,2\% do valor do imóvel - os investidores preferiam deixar o terreno vago, à espera de valorização (Folha do Norte do Paraná, 7 abr. 1974). No caso da infraestrutura, tem-se que esta consiste em um valor de uso que se converte em valor de troca para o mercado. Assim, neste momento, já se sentia o reflexo das ações da CODEMAR no provimento do abastecimento de água e esgotamento sanitário, e mesmo de outros melhoramentos, como a eletrificação - satisfatoriamente atendida na cidade - e o asfaltamento das vias. A Lei Municipal de Loteamentos de 1968 (Lei n625/68) também atuava neste sentido, como foi dito, exigindo a execução de infraestrutura por parte do loteador. A alternativa para a população de baixa renda era ocupar algumas áreas ainda carentes destes serviços ou migrar para cidades vizinhas, como Sarandi, que já ofertava loteamentos precários para atrair esta população.

No ano de 1977, o sistema de abastecimento de água, projetado para ser implantado em duas etapas, dava sinais de esgotamento de sua capacidade. Neste momento, com uma população de cerca de 140.000 habitantes, estima-se que o abastecimento de água já servisse quase $90 \%$ da população. A rápida ampliação do atendimento deste serviço se deve ao fato das obras estarem concluídas na área do plano inicial; o Jardim Alvorada, loteamento de grande proporção, ter sido implantado com a tubulação de abastecimento 
de água já em 1962; e os loteamentos abertos após 1968, terem que contar com a rede por exigência da legislação.

A análise da ocupação urbana deste ano revela um alto grau de adensamento construtivo em praticamente toda área planejada e suas adjacências como a Zona 8, Vila Esperança I, Vila Santo Antônio, Vila Morangueira e parte do Jardim Alvorada. A área central acentuava seu processo de verticalização. O plano inicial já se mostra bastante desconfigurado, com os quadrantes sul e noroeste apresentando crescimento bastante fragmentado e descontínuo, estruturados por antigas estradas rurais que, com a expansão da urbe tornavam-se vias urbanas. O crescimento mais expressivo se dava no quadrante nordeste, onde a malha urbana se expandia de forma mais contínua, em razão da aprovação de loteamentos de maior dimensão e da expansão do setor industrial - com o Parque Industrial I e II - que atraia loteamentos mais populares em seu entorno (Figura 2).

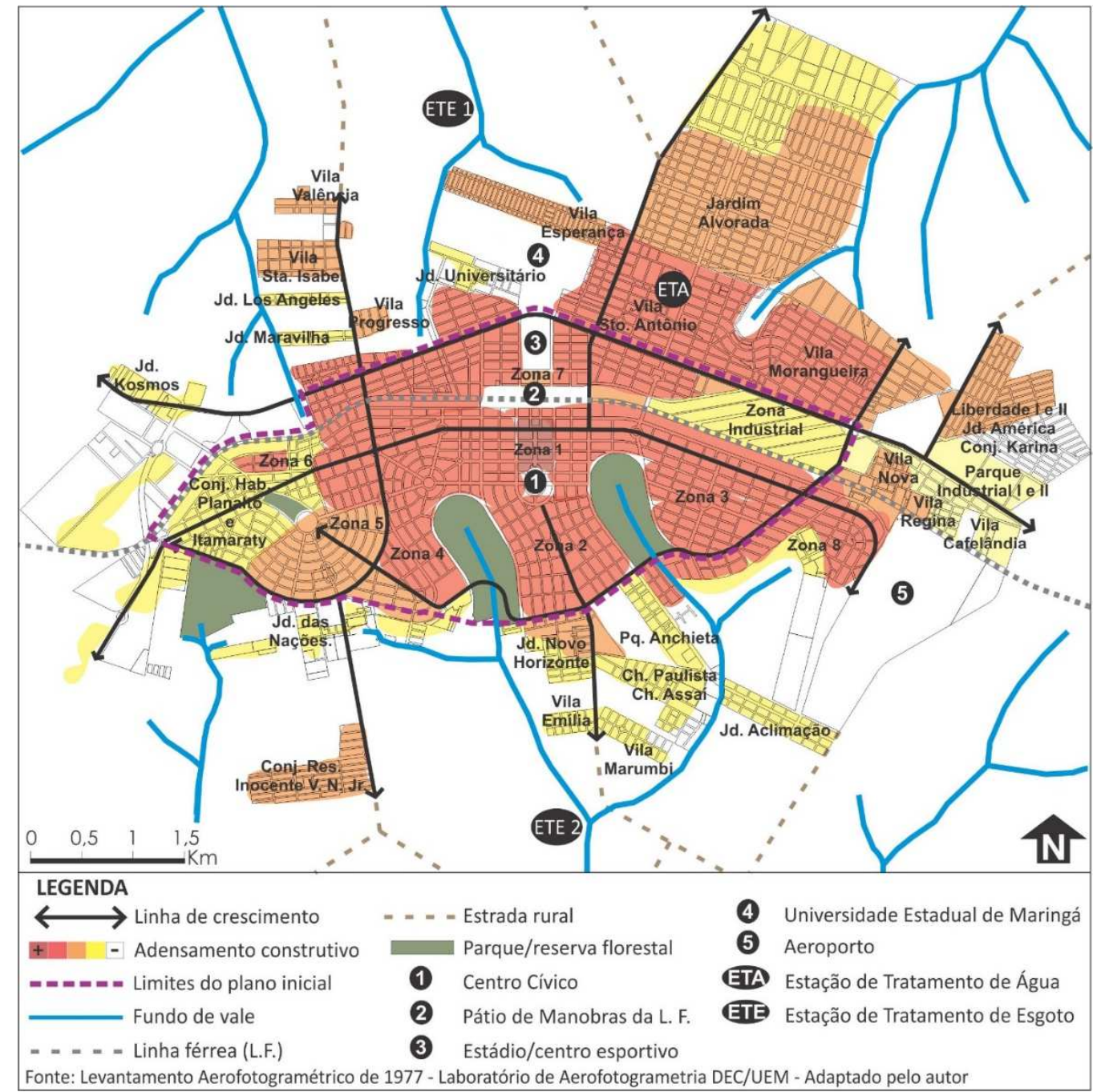

Figura 2 - Forma urbana e adensamento construtivo de Maringá, em 1977 
Em fins de 1977, a situação da água era preocupante. Noticiava-se um racionamento generalizado na cidade, que atingiu até importantes equipamentos como hospitais e o Destacamento do Corpo de Bombeiros. A situação obrigou à adoção oficial de racionamento, até que as obras de ampliação do sistema fossem terminadas. O esquema adotado pela CODEMAR dividia a cidade em 6 conjuntos de bairros, onde cada qual ficaria sem água um dia na semana (O Diário do Norte do Paraná, 6 nov. 1977; 20 nov. 1977). Embora o plano de racionamento, na teoria, não privilegiasse nenhuma porção urbana, aparentemente não foi o que de fato ocorreu, com os bairros de baixa renda sendo os mais afetados. O Jardim Alvorada, que sofria com a falta de água desde julho de 1976, chegava a ficar até três dias sem receber água; e em 1978, noticiou-se que os moradores da Vila Esperança ficavam até 10 dias sem atendimento, tendo que recorrer ao córrego próximo para lavar roupas e buscar água (O Diário do Norte do Paraná, 30 jul. 1976; 10 jan. 1978; 19 fev. 1978). A escassez nos bairros de baixa renda era um fato ainda mais grave em razão de muitas residências não possuírem caixas d'água. Apenas quem ainda possuía poço em seu lote tinha alguma tranquilidade, tendo que frequentemente ceder água aos vizinhos.

As obras da $2^{\text {a }}$ etapa do sistema de abastecimento de água iniciaram em 1978 e só foram finalizadas em 1980, pouco antes dos serviços sanitários serem repassados para a concessionária estadual. Assim, neste período, a falta de água foi comum no município, tendo inclusive adotado um racionamento mais rígido no início de 1979 , onde um conjunto de bairros recebia água nos dias pares e outro conjunto nos dias ímpares (O Diário do Norte do Paraná, 9 fev. 1979). A principal obra desta etapa era a Estação de Recalque Intermediário (ERI) que, juntamente com os novos conjuntos elevatórios no rio Pirapó, possibilitaria a elevação da capacidade de atendimento para até 200.000 habitantes.

Paralelamente à ampliação do sistema de abastecimento, a rede de esgotamento sanitário também se expandia. Entre 1977 e 1980 foram implantados cerca de $80 \mathrm{~km}$ de rede de esgoto, concentrando os serviços nos seguintes bairros: Zona 4, Zona 7, Vila Esperança, Vila Santo Antônio e Jardim Alvorada, a maior parte financiada com verbas do projeto, de âmbito federal, Comunidade Urbana de Recuperação Acelerada I (CURA I) (O Diário do Norte do Paraná, 19 mar. 1982). Embora estivesse prevista uma terceira estação de tratamento para a porção correspondente ao Jardim Alvorada, inicialmente o bairro foi 
atendido pela ETE 1, onde um emissário levava o esgoto a uma Estação de Recalque e, desta, era direcionado à ETE 1 (O Diário do Norte do Paraná, 25 jan. 1979).

O emissário começou a operar no início de 1979. Neste momento as Zonas 1 e 2 encontravam-se completamente atendidas; as Zonas 3, 4, 5, 7 e 8 eram atendidas parcialmente; e o Jardim Alvorada, Vila Esperança e Vila Santo Antônio, começaram a ser atendidos com a inauguração do Estação de Recalque. Esperava-se a liberação do financiamento do projeto CURA II, para execução de mais $40 \mathrm{~km}$ de redes, concluindo o atendimento em grande parte destas localidades. Em 1980, quando houve a entrega da concessão à SANEPAR, já eram mais de 200 km em extensão de rede de esgoto, que serviam um total de 8.960 ligações (O Diário do Norte do Paraná, 26 jun. 79; SANEPAR, 2011).

Em junho 1980 há a completa extinção do controle municipal dos sistemas, por meio da Lei $\mathrm{n}^{\circ}$ 1.379/80, que autorizava o poder executivo a conceder à SANEPAR a exploração e operação dos sistemas sanitários. Neste momento o município havia terminado, há pouco, a ampliação do sistema de abastecimento de água, com a execução da ERI e de novos conjuntos motor-bomba na captação, elevando a capacidade de fornecimento de água tratada para 200.000 habitantes; e, na área do esgotamento sanitário, acabara de inaugurar a Estação de Recalque, que levaria o esgoto de bairros como o Jardim Alvorada até a ETE 1. Em números de atendimento destas redes, haviam 27.842 ligações de água - mais de $90 \%$ da cidade atendida - e 8.960 ligações de esgoto - o que representava aproximadamente $32 \%^{2}$. A porcentagem de atendimento conseguida pela gestão municipal, se mostra próxima da média brasileira no ano de 1980 quando, de acordo com Bier, Paulani e Messenberg (1988), em 1984, 80,3\% da população tinha acesso à água tratada e, em 1980, 32\% eram atendidos pela coleta de esgoto.

Desta forma, no momento de transferência à concessionária estadual, o município tinha acabado de investir grandes montantes financeiros em importantes obras para ampliação do sistema, solucionando o problema de racionamento de água e iniciando o atendimento de esgoto em áreas fora dos limites do plano inicial. Ainda assim, o motivo alegado pelo então prefeito João Paulino Vieira Filho foi a escassez de recursos para a continuidade de

\footnotetext{
${ }^{2} \mathrm{O}$ descompasso entre o atendimento de abastecimento de água e coleta e tratamento de esgoto no Brasil é histórico, e perdura até os dias atuais. No Brasil, 83,3\% da população tem acesso à água tratada e apenas $50,3 \%$ à coleta de esgoto (SNIS, 2015).
} 
melhorias nas redes. Afirmava haver necessidade de investimentos sistemáticos em barragens, motores, bombas, adutoras, decantadores e floculadores que, com os recursos cada vez mais escassos, do Governo Federal, tornaram inviável a manutenção dos sistemas no âmbito municipal (O Jornal de Maringá, 13 jun. 1980).

Aparentemente, a transição para a concessionária estadual não foi tranquila na Câmara, tendo passado por votação apertada entre os vereadores, com 11 votos a favor e 10 contra (O Jornal de Maringá, 13 jun. 1980). Os argumentos dos contrários à transferência eram de demissão sumária de mais de uma centena de empregados da companhia municipal ${ }^{3}$ e o encarecimento dos serviços. A SANEPAR por sua vez, investiu maciçamente em propagandas na mídia local, garantindo a ampliação do sistema instalado e a manutenção dos funcionários municipais, fatos estes contemplados na Lei $n^{\circ} 1.379 / 80$ (BASSI, 1981).

A respeito das exigências de ampliação previstas na supracitada lei, vale ressaltar que os 50 mil metros de rede de água e 100 mil metros de rede de esgoto, deveriam ser implantados prioritariamente nas Zonas 3, 4, 5, 6 ,7, 8 e Zona de Armazéns, ou seja, novamente o poder público reforçava a distinção entre a porção planejada da cidade e os loteamentos posteriores. Findava-se, assim, a gestão municipal dos sistemas sanitários, inserindo a empresa estadual como novo ator hegemônico destes serviços.

\section{Conclusão}

O encaminhamento das redes sanitárias no período analisado (1962-1980) parece seguir a curva de evolução lógica de que fala Serratosa (1998), em que há um período de exclusividade, onde poucos têm acesso ao serviço; um segundo momento de massificação do serviço, com a rede se estabelecendo no território; e, por fim, um final lento, que corresponde à saturação, quando ao menos $95 \%$ da população já é atendida.

\footnotetext{
${ }^{3}$ Em meio à crise do sistema de abastecimento, a CODEMAR foi extinta em 1976, sendo incorporada à Secretaria Municipal de Expansão Econômica pelo Decreto n¹3/1976. Em 1978, houve nova mudança com a Lei $n^{\circ} 1229 / 1978$, que criou o Serviço Autárquico de Água e Esgoto. Na prática, manteve-se a mesma estrutura de funcionamento, alterando-se apenas a contabilidade e a razão social.
} 
Neste sentido, no caso do abastecimento de água, tem-se o primeiro momento entre 19691970, quando se privilegiou o atendimento das áreas de maior interesse econômico do município - centro e Zona 2. O segundo momento, de massificação, ocorre entre 19711977, quando o serviço irradia-se das áreas inicialmente atendidas, sendo atraído principalmente pela demanda, com uma clara intenção de estruturar primeiramente a área planejada. Após, o atendimento se estendeu às áreas de expansão mais significativas, como a Vila Morangueira e o Jardim Alvorada. Na fase final, entre 1978-1980, se encaminhava para mais de $90 \%$ da população atendida, com a rede se estabelecendo nas áreas de expansão de menor expressão e menos consolidadas. Esta fase final coincide com a saturação do sistema de abastecimento, que teve que passar por ampliações antes do previsto no projeto de abastecimento.

O esgotamento sanitário seguiu uma lógica semelhante, porém com uma evolução mais lenta no território. Novamente o atendimento é iniciado na área central e Zona 2; seguido pelas demais localidades dentro do limite da área planejada; e, por fim, as áreas de expansões mais consolidadas. Assim, ainda que a densidade seja um fator intrínseco ao desenvolvimento das redes no espaço urbano, por ser nestes espaços que elas encontram sua justificativa econômica e social para se desenvolverem (DUPUY, 1998), no caso analisado, o padrão socioeconômico parece ter sido fator de igual ou maior relevância.

Este fato fica evidente, por exemplo, com o fato de a Zona 2 - bairro de alto padrão - ser historicamente beneficiado. À época do início do abastecimento de água, esta localidade não era o bairro de maior densidade habitacional - sendo estes as Zonas 3 e 7 -, nem tecnicamente a área mais próxima da ETA - que seriam o Jardim Alvorada, Vila Morangueira, Vila Santo Antônio e Zona 7. Ainda que a Zona 2 já tivesse as tubulações instaladas, o mesmo ocorria com o Jardim Alvorada e com outros loteamentos implantados após 1968. Vale destacar que, neste momento, o atendimento nos bairros de menor renda se fazia mais urgente, uma vez que esta população não podia arcar com os custos dos poços semiartesianos que a população de maior poder aquisitivo tinha acesso.

Após a implantação do serviço no centro - área que encontra sua justificativa tanto pela densidade construtiva quanto pelo valor econômico - e da Zona 2, privilegiou-se as áreas dentro do limite do plano inicial. Esta dinâmica favoreceu a distinção entre a área planejada e as áreas de expansão, onde a primeira se apresentava como a "cidade servida", e a 
segunda, a "cidade sem acesso", recebia os melhoramentos com atraso. Estes distintos espaços topológicos formados foram reflexo da atuação do poder municipal que, fruto da lógica capitalista caracterizada pela disputa de interesses, vantagens locacionais e luta de classes, privilegiou determinadas localidades - e grupos sociais - em detrimento de outras.

Neste sentido, nota-se a atuação contraditória do Estado, descrito por Corrêa (1999) que, no âmbito municipal, legitima e materializa os conflitos de interesses de diferentes setores e classes, promovendo a distribuição desigual de bens e serviços, num processo que tende a privilegiar as camadas de alta renda. A implantação dos serviços sanitários parece confirmar esta tendência pois, as facilidades trazidas e o impacto na saúde pública e qualidade de vida, proporcionada por estas - enquanto valores de uso -, irão se refletir no valor de troca do espaço, o que explica o interesse do mercado imobiliário por estes serviços.

No caso de Maringá, reforçavam esta distinção, além da dinâmica de implantação das redes já descrita, ações como o racionamento de água desigual - verificado na prática -, nos quais os bairros periféricos - e de menor renda - eram mais afetados; a opção pela execução da ETE 2, localizada na porção sul da cidade e que possuía condições técnicas de atender à maior porção da área planejada, em detrimento da ETE 1, na porção norte, onde se localizava as camadas de menor renda; e mesmo o contrato de extensão da rede com a SANEPAR, priorizando a efetivação do atendimento na área planejada.

Tais políticas fortaleceram a dicotomia entre a porção planejada e áreas de expansão, resultado da falta de neutralidade das ações do poder municipal. Desta forma, é possível afirmar que, no caso de Maringá, valor do solo e classe social foram variáveis mais importantes do que a demanda e a viabilidade técnica, na implantação das redes sanitárias.

\section{Referências bibliográficas}

ANDRADE, Carlos Roberto Monteiro de; et alli. O urbanismo do engenheiro Jorge de Macedo Vieira. Painéis da Exposição. IV Bienal Internacional de Arquitetura de São Paulo, São Paulo, 1999.

BARBOSA, Leonardo C. As redes técnicas sanitárias na estruturação do território: análise da cidade de Maringá-PR, entre 1947-1980. 2016. 345f. Tese (Doutorado em Arquitetura e Urbanismo), Instituto de Arquitetura e Urbanismo, Universidade de São Paulo, São Carlos, 2016 a. 
BARBOSA, Leonardo C. A Atuação do setor privado nos sistemas de abastecimento de água em Maringá-PR: conflitos e repercussão na estruturação do território. In XIV Seminário de História da Cidade e do Urbanismo (XIV SHCU), São Carlos, 2016. Anais XIV SHCU, 2016b, p. 346-355.

BASSI, Giácomo. Incorporações de Sistemas Regionais de Saneamento. SANEPAR - Companhia de Saneamento do Paraná. Revista Propaganda, São Paulo, dez. 1981., no 305, p. 25-28.

BIER, Amaury G.; PAULANI, Leda M.; MESSENBERG, Roberto P. A Crise do Saneamento No Brasil:Reforma Tributaria, Uma Falsa Resposta. Pesquisa e Planejamento Econômico, 1988, vol. 18, no 1, p. 161-196.

CASTELLS, Manuel. A Sociedade em Rede. vol. 1, 8a ed.. São Paulo: Paz e Terra, 2005.

CODEM - COMISSÃO DE DESENVOLVIMENTO MUNICIPAL. Plano Diretor de Desenvolvimento de Maringá. Curitiba, 1967.

CORDOVIL, Fabíola C. de S.. A aventura planejada: engenharia e urbanismo na construção de Maringá, PR 1947 - 1982. 2010. 636f. Tese (Doutorado em Arquitetura e Urbanismo). Escola de Engenharia de São Carlos, Universidade de São Paulo, São Carlos, 2010.

CORRÊA, Roberto L.. O Espaço Urbano. 2ª ed.. São Paulo: Ática, 1999.

DUPUY, Gabriel. El urbanismo de las redes. Teorias y métodos. Barcelona: Oikos-Tau, 1998.

E. T. AlVARO CUNHA. Projeto do Sistema de Abastecimento de Água. Relatório e Especificações Técnicas. São Paulo, 1963.

FOLHA DO NORTE DO PARANÁ. Edições de (impressas): 7 abr. 1974; 10 nov. 1974.

GONÇALVES, José H. R. Quando a imagem publicitária vira evidência factual: versões e reversões do Norte (Novo) do Paraná - 1930/1970. In MACEDO, Oigres L. C. De M.; CORDOVIL, Fabíola C. De S.; REGO, Renato L. (orgs.). Pensar Maringá: 60 anos do Plano. Maringá: Massoni, 2007. ISBN: 978-85-88905-62-7.

LAMAS, José M. R. G.. Morfologia urbana e o desenho da cidade. 3a ed.. Lisboa: Fundação Calouste Gulbenkian e Fundação para a Ciência e Técnologia, 2004.

LEFEBVRE, Henri. O direito à cidade. São Paulo: Centauro, 2001.

LUZ, France. O Fenômeno Urbano numa Zona Pioneira: Maringá. Maringá: Prefeitura, 1997.

MARINGÁ ILUSTRADA (revista). Edição Comemorativa do Jubileu de Prata. Maringá, Maio de 1972.

MARINGÁ, P. M.. Lei $n^{\circ}$ 236/62 - Constitui uma sociedade de economia mista - Companhia de Desenvolvimento de Maringá - CODEMAR. Maringá, 1962.

MARINGÁ, P. M.. Lei $\mathrm{n}^{\circ}$ 384/65 - Disciplina funcionamento de poços aartesianos e semi-artesianos no perímetro urbano da cidade. Maringá, 1965.

MARINGÁ, P. M. Lei n 1379/80 - Autoriza o poder executivo a conceder, com exclusividade, à Companhia de Saneamento do Paraná - SANEPAR -, a exploração e operação dos sistemas de abastecimento de água e de esgotamento sanitário municipais e dá outras providências. Maringá, 1980.

MOTA, Lúcio T.. História do Paraná: ocupação e relações interculturais. Maringá: EDUEM, 2005.

MONBEIG, Pierre. Pioneiros e fazendeiros de São Paulo. São Paulo: Ed. Hucitec, 1984.

NUNES, Layane A. Para além do Plano de Jorge de Macedo Vieira: a expansão urbana de Maringá de 1945 a 1963. 2016. 369f. Tese (Doutorado em Arquitetura e Urbanismo), Instituto de Arquitetura e Urbanismo, Universidade de São Paulo, São Carlos, 2016.

O DIÁRIO DO NORTE DO PARANÁ, edições de (impressas): 9 out. 1974; 12 nov. 1974; 13 nov. 1974; 3 abr. 1975; 8 abr. 1975; 10 abr. 1975; 30 jul. 1976; 6 nov. 1977; 20 nov. 1977; 10 jan. 1978; 19 fev. 1978; 9 fev. $1979 ; 25$ jan. 1979; 26 jun. 1979; 19 mar. 1982 (suplemento especial).

O JORNAL DE MARINGÁ, edições de (impressas): 6 jan. 1963; 23 fev. 1969; 13 jun. 1980.

RAFFESTIN, Claude. Por uma geografia do poder. São Paulo: Ática, 1993.

REGO, Renato L.. As cidades plantadas: os britânicos e a construção da paisagem do norte do Paraná. Londrina: Humanidades, 2009. 
REZENDE, Sonaly; HELLER, Léo. O Saneamento no Brasil: Políticas e interfaces. Belo Horizonte: Editora UFMG, Escola de Engenharia da UFMG, 2002.

SANTOS, Milton. A natureza do espaço: técnica e tempo, razão e emoção. São Paulo: Edusp, 2006.

SANTOS, Milton. Por uma outra globalização: do pensamento único à consciência universal. Rio de Janeiro: Record, 2008.

SANEPAR - Companhia de Saneamento do Paraná (site institucional). Notícias. Maringá ultrapassa o índice de 96\% de coleta de esgoto. 2011. Disponível em: http://site.sanepar.com.br/noticias/maringa-ultrapassa-oindice-de-96-de-coleta-de-esgoto Acesso em: 03 nov. 2015.

SECCHI, Bernardo. Primeira lição de urbanismo. São Paulo: Perspectiva, 2007.

SERRATOSA, Albert. Prólogo (Prólogo e supervisão da tradução da edição em espanhol). 1996. In DUPUY, Gabriel. El urbanismo de las redes. Teorias y métodos. Barcelona: Oikos-Tau, 1998.

SNIS - Sistema Nacional de Informação sobre Saneamento. Diagnóstico dos Serviços de água e esgoto - 2015. 2015. Disponível em: http://www.snis.gov.br/diagnostico-agua-e-esgotos/diagnostico-ae-2015 Acesso em: 16 mai. 2017.

VILLAÇA, Flávio. Espaço Intra-urbano no Brasil. São Paulo: Studio Nobel: FAPESP: Lincoln Institute, 2001.

TARR, Joel A. The evolution of the urban infrastructure in the Nineteenth and Twentieth Centuries. In HANSON, Royce (ed.). Perspectives on Urban Infrastructure. Washington, D.C.: National Academic Press, 1984. 